\title{
Evaluating the Impact of Oxygen Concentration and Plating Density on Human Wharton's Jelly-Derived Mesenchymal Stromal Cells
}

\author{
Yelica López ${ }^{\dagger}$, Kiran Seshareddy ${ }^{\dagger}$, Elizabeth Trevino, Josiah Cox ${ }^{\ddagger}$ and Mark L. Weiss ${ }^{*}$ \\ Department of Anatomy and Physiology, Kansas State University, College of Veterinary Medicine, Manhattan, KS, \\ 66506, USA
}

\begin{abstract}
Isolates of mesenchymal stromal cells (MSCs) contain a mixed cell population of stem cells, multipotent and unipotent progenitors, and differentiated cells. It is speculated that the useful subpopulation for tissue engineering and cell therapy will be the multipotent progenitor cells or the stem cells. The colony forming unit-fibroblast (CFU-F) assay is an in vitro assay for clonogenicity, which is one property of the stem/progenitor cell population of MSCs. Our goal was to generate standard protocols that would permit the expansion and maintenance of CFU-F. Previous work reported that low plating density and/or exposure to $5 \%$ oxygen $v$ s. $21 \%$ oxygen increased proliferation rate and enhanced expansion of MSCs. Here, we characterized the effect of both plating density and oxygen concentration on MSCs derived from Wharton's jelly (WJCs). We found that reducing oxygen concentration from $21 \%$ (room air) to $5 \%$ during expansion increased cell yield and maintained CFU-F, without affecting the expression of surface markers or the differentiation capacity of WJCs. In addition, reducing plating density from 100 cells $/ \mathrm{cm}^{2}$ to $10 \mathrm{cells} / \mathrm{cm}^{2}$ increased CFU-F frequency. Therefore, plating density and oxygen concentration are two important variables that affect the expansion rate and frequency of CFU-F of WJCs. These results suggest that these two variables might be used to produce different input populations for tissue engineering or cellular therapy.
\end{abstract}

Keywords: Mesenchymal stromal cells, CFU-F, Cell therapy, Cell expansion.

\section{INTRODUCTION}

Mesenchymal stromal cells (MSCs) are defined by their plastic adherence, their expression of characteristic surface markers antigens and their in vitro differentiation potential towards bone, cartilage and fat [1]. MSCs may be isolated from most adult and fetal tissues (perhaps as pericytes) [2-4]. Owing to their ability to differentiate into cells of mesenchymal lineages and to their unique immune properties, MSCs have been tested in clinical trials for a variety of diseases including graft $v s$. host disease (GVHD), myocardial infarction, osteogenesis imperfecta, and other diseases [5,6]. In the case of myocardial infarction, a meta-analysis of clinical trials reported that bone marrow (BM) cells have a positive functional effect following myocardial infarction with no increased risk [7]. Since MSCs are a mixed cell population and it is unknown which cell fraction is responsible for their clinical effects, it has been speculated that in vitro expansion protocols may be used to produce more potent cells [8].

While it is unknown which cells in the MSC isolates are most potent clinically, several hypotheses about which is the effective MSC population have emerged. One hypothesis states that MSCs with the highest proliferation would be most useful clinically [9]. Since higher CFU-F in BM transplants is correlated with better functional recovery after

*Address correspondence to this author at the Department of Anatomy and Physiology, Kansas State University, Coles Hall, room 105, Manhattan, KS 66506, USA; Tel: 785-532-4520; Fax: 785-532-4557; E-mail: weiss@ @et.kstate.edu

'These authors contributed equally to this work.

Current address: University of Kansas Medical Center, 3900 Rainbow Avenue, Kansas City, KS myocardial infarction [10], another hypothesis is that high colony forming unit-fibroblast (CFU-F) frequency indicates the effective isolates. Another hypothesis states that MSCs from younger individuals are superior to those from older people since the capacity of BM-MSCs to proliferate and differentiate decreases with age and CFU-F frequency decreases with donor age, too [11]. In addition, prior disease in the donor may have negative effects on BM-MSCs $[12,13]$. To synthesize these hypotheses: MSCs from young, disease-free individuals that are expanding rapidly and contain high CFU-F may be the most potent MSCs for cellular therapy.

We speculate that MSCs derived from Wharton's jelly of the umbilical cord (WJCs) will be potent for cellular therapy, since WJCs are collected non-invasively and painlessly from disease-free newborns [14]. Furthermore, WJCs meet the definition of MSCs and they expand faster than BM-MSCs $[15,16]$, and our pilot work and work from JE Davies laboratory indicate that WJCs have higher CFU-F frequency than has been reported for BM-MSCs (López et al., ISSCR abstract 2010; [17]). Pre-clinical data suggests that WJCs may have utility in treating immune disorders such as GVHD [18-23], or other immune diseases [24]. While WJCs have greater expansion potential and higher CFU-F frequency compared to BM-MSCs, they have yet to be clinically tested.

In order to optimize cell preparation for therapy, here, we evaluated the effect of oxygen concentration and plating density on WJCs during expansion. We hypothesized that MSCs cultured in 5\% oxygen tension and at low density (10 cells $/ \mathrm{cm}^{2}$ ) would maintain CFU-F frequency and grow faster compared to WJCs maintained at $21 \%$ oxygen and high 
density $\left(100\right.$ cells $\left./ \mathrm{cm}^{2}\right)$. We found a potent effect of oxygen tension and plating density on WJCs expansion and did not find an effect on differentiation capacity or surface marker expression. These optimized methods permit rapid expansion of WJCs for pre-clinical and clinical evaluation.

\section{MATERIAL AND METHODS}

\section{Human Subjects}

Kansas State University's Institutional Review Board (IRB) reviewed this work (protocol \# 5189, 3515 and 3996). After birth, the umbilical cord was placed in sterile saline and stored at $4^{\circ} \mathrm{C}$ until it was processed. The umbilical cord was processed within 24 hours of birth in a biosafety cabinet (BSC) using universal precautions (BSL2).

\section{Isolation and Expansion of WJCs}

A method for isolation of WJCs has been described [14]. A modification of those methods is described here. The umbilical cord was rinsed with Dulbecco's Phosphate Buffered Saline (DPBS, Invitrogen, cat \# 14190-250) to remove as much blood as possible. The cord was cut into 3-5 $\mathrm{cm}$ lengths and rinsed again. The cord was slit length-wise and the blood vessels were removed. Tissue was digested in a collagenase and hyaluronidase enzyme solution at $37^{\circ} \mathrm{C}$ for 45 minutes (Collagenase Type I, Invitrogen catalog \# 17100017 @300units/ml; Hyaluronidase, Fisher catalogue \# ICN15127202@1mg/ml in Phosphate Buffered Saline with $3 \mathrm{mM} \mathrm{CaCl} 2$ ). Next, the tissue was transferred into Stomacher bags (Brinkmann catalogue \# 030020278), into the inner tissue filter bag, along with $25 \mathrm{ml}$ of enzyme solution. The air in the bag was removed. The bag was heat-sealed and processed in the Stomacher (Stomacher 400, Brinkmann catalogue \# 030010159) at $150 \mathrm{rpm}$ for 10 minutes at $37^{\circ} \mathrm{C}$. The bag was removed, and the outside was sprayed with $70 \%$ alcohol and placed inside the BSC. The cells and enzyme solution was collected from the outer bag and centrifuged at $1000 \mathrm{rpm}$ for 5 minutes at $20^{\circ} \mathrm{C}$. The supernatant was discarded and the pellet was suspended in $1 \mathrm{ml}$ of growth medium. The red blood cells (RBCs) in the pellet were lysed with Sigma red blood cell lysing buffer (catalogue \# 7757) using the manufacturer's protocol. Live cell count was done using a hemocytometer. The cells were plated on tissue culture plastic at a density of 10,000 live cells $/ \mathrm{cm}^{2}$. The cells were grown to $85-90 \%$ confluence prior to passage $0->1$. To passage, the cells were rinsed twice with DPBS, followed by $0.05 \%$ Trypsin/EDTA for 5 minutes at $37^{\circ} \mathrm{C}$. The trypsin was inactivated by adding 3 volumes of growth medium and the cells were pelleted by centrifugation.

For Project 1, cells were counted and transferred to a new plate or flask at a concentration of 10,000 cells per $\mathrm{cm}^{2}$ in fresh medium and incubated at $37{ }^{\circ} \mathrm{C}$, saturating humidity and $5 \% \mathrm{CO}_{2}$. The plates and/or flasks were checked for confluence every day and the cells were fed every other day by removing half the medium and replacing it with fresh medium. Cells were grown for four days prior to passage. For serum-free conditions, the cells were grown on $0.1 \%$ gelatin-coated flasks. The standard growth medium used is a $2 \%$ serum DMEM medium described previously [14] and the serum-free medium used was previously described by
Battula et al., [25]. For Project 2, CFU-F assays were performed by plating 6 replicates of 100,500 or $1000 \mathrm{WJCs}$ into 6 well plates $\left(9 \mathrm{~cm}^{2}\right.$ surface area) to yield plating density of approximately 10,50 and 100 cells per $\mathrm{cm}^{2}$. In a pilot work, plating at densities higher than 100 cell per $\mathrm{cm}^{2}$ yield too many colonies to count at 7 days. After 7-10 days of culture, medium was removed and the plates washed with DPBS, and cells were fixed with methanol for $5 \mathrm{~min}$. The plates were air-dried and stained with cresyl violet, rinsed, and air-dried. CFU-F colonies $(1-8 \mathrm{~mm}$ diameter $)$ were counted manually by two investigators who were blinded to the experimental conditions. After all counting was completed, the data was decoded and averaged. The CFU-F assays were performed between passage 1-6 on eight isolates in more than three independent trials. In a "random" subset of the CFU-F plates at the 10 and 50 cells per $\mathrm{cm}^{2}$ density, the average size of the colonies was determined independently by two investigators who were blind to the experimental conditions. Using established criteria for colony selection, colony size was determined by measuring a random selected axis diameter using an eyepiece micrometer at an overall magnification of $1 \mathrm{x}$. At least 70 , nonoverlapping colonies were measured by each investigator. Each colony was counted once by an investigator. No attempt was made to insure that the two investigators counted the same colonies. Colony Forming Efficiency (CFE) was calculated as the number of colonies per the number of plated WJCs.

\section{Differentiation of MSC}

Osteogenic differentiation was performed on WJCs at either passage 4 and 8 . Briefly, $2 \times 10^{4}$ WJC were cultured in 24 well Falcon plates. The growth medium was replaced with Invitrogen Osteogenic medium for 21 days of culture. The cells were then fixed with methanol and stained with von Kossa stainas previously described [26]. Chondrogenic differentiation was performed on WJCs at either passage 4 and 8 . Briefly, $4 \times 10^{5}$ WJCs were cultured either in 3D culture as a pellet in a $15 \mathrm{ml}$ centrifuge tube or in 2D culture in a 24 well tissue culture plates. The growth medium was replaced with Stem Cells Technologies Chondrogenic medium for 21 days of culture. The cells in culture plates were fixed and stained with Mason's Trichrome stain.

\section{Project 1: Effect of Serum-Free Medium and 5\% Oxygen on Growth Rate}

The cells from P1-P6 were grown in four growth conditions - 1) $21 \%$ oxygen (room air) and standard growth medium with $2 \%$ serum, 2) $21 \%$ oxygen and serum-free medium, 3) 5\% oxygen and standard growth medium with $2 \%$ serum and 4) $5 \%$ oxygen and serum-free medium. The same isolate was processed for each of the four conditions using 2 identical NuAire AutoFlo two gas incubators (5\% $\mathrm{CO}_{2}, 21 \%$ or $5 \% \mathrm{O}_{2}, 37^{\circ} \mathrm{C}, 90 \%$ humidity). The serum-free medium was formulated as described previously by Battula V. et al.: Knockout DMEM medium (Invitrogen 10829) with $20 \%$ Knockout serum replacer (Invitrogen 10828-028), 1mM L-Glutamine, (Sigma 49419), $0.1 \mathrm{mM}$ B-mercaptoethanol, (Sigma, M7522); 1\% non-essential amino acids, (Invitrogen 11140); $5 \mathrm{ng} / \mathrm{ml}$ bFGF, (Invitrogen 13256-029) [25]. At each passage, 250,000 cells were plated in a T-25 flask and 
cultured for four days in each of the four culture conditions and then counted using a hemocytometer and the Trypan blue exclusion method to determine live/dead cells. The "standard growth medium with $2 \%$ serum" has been described previously [14].

\section{Growth Curve and Population Doubling Time}

To obtain the cell proliferation growth curve and calculate the mean population doubling time, 250000 cells were plated in T-25 flasks (Corning catalogue \# 430639), and fed every 2 days. After 4 days of growth, the cells were detached and counted using a hemocytometer. Population doubling was calculated using the formula:

Inverse of $\frac{\log (\text { final cell number })-\log (\text { initial cell number }) x 3.32}{\text { Time difference }(T 2-T 1)}$

\section{Flow Cytometry}

Flow cytometry was used to examine surface markers: CD13, CD44, CD49e, CD90 and CD105. The cells were lifted for passaging and resuspended in DPBS at 1-2 million cells $/ \mathrm{ml}$. An aliquot of the cell suspension was added to $12 \mathrm{x}$ $75 \mathrm{~mm}$ Falcon polystyrene tubes. The appropriate amount of conjugated antibody or isotype control was added to each tube (PE isotype control IgG1, BD Biosciences catalogue \# $555749 @ 1 \mu \mathrm{l} / 100 \mu 1$ cell suspension; FITC isotype control IgG2b, BD Biosciences catalogue \# 556655 @ 10 $\mu 1 / 100 \mu 1$ cell suspension; PE CD13 IgG1, BD Biosciences catalogue \# $555394 @ 10 \mu 1 / 100 \mu 1$ cell suspension; PE CD44 IgG2b BD Biosciences catalogue \# 556655 @ 10 $\mu 1 / 100 \mu 1$ cell suspension; PE CD49e IgG1, BD Biosciences catalogue \# 555617

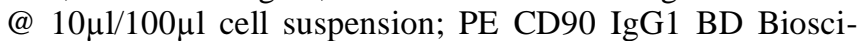
ences catalogue \# 555596 @ 5 $\mu 1 / 100 \mu 1$ cell suspension; PE CD105 IgG1, Fitzgerald catalogue \# RDI CD105NPE @ $3 \mu 1 / 100 \mu 1$ cell suspension). Tubes were incubated at room temperature in the dark for 15-20 min. After the incubation, the cells were washed with PBS and the results were obtained by reading the output of a FACSCalibur flow cytometer. For each tube, 10000 events were collected and the data was analyzed using Cell Quest software. Following adjustment of forward and side scatter to exclude debris and include WJCs, isotype (Negative) control gates were set at $1 \%$.

\section{Immunofluorescence Evaluation}

For immunofluorescence, plates were washed with DPBS, fixed with $4 \%$ paraformaldehyde for 5 minutes at room temperature. Nonspecific staining was blocked by incubating with 5\% normal goat serum (NGS) for 30 minutes. Samples were incubated with conjugated antibodies at room temperature in the dark for 20 minutes. Cells or colonies were screening using conjugated antibodies against human PE-CD271 (BD Pharminogen catalogue\# 557196), FITC-CD44 (BD Biosciences catalogue\# 555478), or rabbit anti-nestin (Chemicon). All antibodies were used at 1:1001:200 dilution. After incubation, plates were washed twice with DPBS. In the case of nestin, an AlexaFluor 488 secondary anti-rabbit antibody was used to localize the primary antibody, followed by triple rinsing with DPBS. As a negative control, WJCs were staining using isotype control anti- bodies (PE mouse IgG BD Biociences catalogue\# 555743) and FITC mouse IgG (BD Biociences catalogue\# 555748). Cell nuclei were stained with $1 \mu \mathrm{g} / \mathrm{ml}$ 4'-6-Diamidino-2phenylindole (DAPI) for five minutes and plates were rinsed with DPBS. Fluorescence was examined using a Nikon Eclipse TE2000-S microscope equipped with epifluorescence filters and micrographs taken with a Roper CoolSnap ES using Metamorph software.

\section{Telomerase Activity}

Telomerase expression was evaluated by telomerase repeat amplification protocol (TRAP) using a commercial kit (TRAPeze ${ }^{\circledR}$ XL Telomerase Detection Kit, MILLIPORE catalogue\# S7707) according to manufacturer's protocol. At passage 3 , cells were detached and $2 \times 10^{6}$ cells were used for TRAP analysis. Positive control cells were embryonic stem cells (ESCs, provided by J. Hong).

\section{Semi-Quantitative RT-PCR}

Total cellular RNA was extracted using the Qiagen RNeasy miniPrep kit or by TRIZOL LS using the manufacturers' protocol. The RNA extraction was followed by DNase treatment. Complementary DNAs to mRNA were generated by reverse transcription of $2 \mu \mathrm{g}$ of total RNA using oligo dT12-18 as a template and Superscript II reverse transcriptase according to the manufacturer's instructions. Following first strand synthesis, the sample was treated with RNase H. Semi-quantitative RT-PCR was performed in duplicate at two different DNA loading concentrations: $2 \mathrm{ng}$ and $20 \mathrm{ng}$. PCR amplification was performed using a BioRad iCycler iQ5 was performed as follows: $95^{\circ} \mathrm{C}$ for $5 \mathrm{~min}$, followed by 40 cycles; each cycle consisted of $95^{\circ} \mathrm{C}$ for 30 $\mathrm{sec}, 60^{\circ} \mathrm{C}$ for $30 \mathrm{sec}$, and $72^{\circ} \mathrm{C}$ for $45 \mathrm{sec}$, and a final extension of $72^{\circ} \mathrm{C}$ for 5 minutes. PCR primers were designed using Primer 3 software (Gene, primer pairs, amplicon size are listed in Table 1). PCR primers for HAS1, HAS2, HAS3, Oct4, Nanog, Cadherin 2, GD2 synthase, beta-actin were validated in pilot work. Positive and negative control RNA was collected from human teratocarcinoma cells (NTera2 cells, ATTC), human bone marrow mesenchymal stromal cells at P1 and P4 (Osiris), and human fibroblasts (ATCC). The threshold count, $\mathrm{Ct}$, was determined using Sybr green signal and the iCycler software version 3.1. A $\Delta \mathrm{Ct}$ value was calculated by subtracting beta-actin $\mathrm{Ct}$ value from the $\mathrm{Ct}$ value of the gene of interest.

Table 1. Flow Cytometry Results

\begin{tabular}{|c|c|c|c|c|}
\hline & $\mathbf{2 1 \%}+\mathbf{G M}$ & $\mathbf{2 1 \%}+\mathbf{S F M}$ & $\mathbf{5 \%}+\mathbf{G M}$ & $\mathbf{5 \%}+\mathbf{S F M}$ \\
\hline \hline $\mathrm{CD} 13$ & $68 \%+10$ & $67 \%+12$ & $47 \%+11$ & $67 \%+12$ \\
\hline $\mathrm{CD} 44$ & $84 \%+7$ & $88 \%+3$ & $64 \%+15$ & $64 \%+14$ \\
\hline $\mathrm{CD} 49 \mathrm{e}$ & $76 \%+14$ & $84 \%+15$ & $70 \%+14$ & $52 \%+14$ \\
\hline $\mathrm{CD} 90$ & $96 \%+2$ & $92 \%+4$ & $85 \%+7$ & $82 \%+8$ \\
\hline $\mathrm{CD} 105$ & $81 \%+9$ & $80 \%+7$ & $60 \%+14$ & $53 \%+23$ \\
\hline $\mathrm{N}=4$
\end{tabular}

\section{Statistics}

Analysis of variance was used to test the significance of main effects and interaction terms. After finding a significant 
main effect or interaction, post hoc testing was performed to evaluate planned comparisons using Scheffe's test. Statistical significance was set at alpha $<0.05$.

\section{RESULTS}

\section{WJC Isolates}

For Project 1, eight cords (five male and two female and one cord of unknown sex) were used. WJC isolates were collected and held overnight prior to isolating WJCs $(5 / 7$ cords obtained after normal vaginal delivery, 1/7 cords obtained after Caesarian-section, 1/7 cord obtained after unknown delivery method, average cord length $52 \mathrm{~cm}$, average of 790,000 cells from each umbilical cord at P0, average of 15,192 cells isolated/cm length). For Project 2, eight cords (four male and four female) were used. Umbilical cords were collected and processed within 24 hours of birth.

Randomly selected WJCs isolates that were expanded in $21 \%$ oxygen or $5 \%$ oxygen were confirmed to differentiate along the chondrogenic and osteogenic lineages using nonquantitative analysis. Oxygen concentration did not affect differentiation to chondrogenic or osteogenic lineages (see Fig. 1).

\section{Project 1: Effect of Oxygen Concentration and Serum- Free Medium on in Vitro Expansion}

Fig. (2) shows cumulative population doubling of WJCs over passages 2-6 when the cells were grown in $5 \%$ or $21 \%$ oxygen, and in two different expansion media: standard growth medium with $2 \%$ serum or serum-free medium (SFM). ANOVA revealed that main effect: Oxygen Concentration was significant $\left(\mathrm{F}_{1,12}=214.2, \mathrm{p}<0.01\right)$, the main effect: Medium was not significant $\left(\mathrm{F}_{1,12}=3.8, \mathrm{p}>0.05\right)$, the repeating measures term: Passage was significant $\left(\mathrm{F}_{4,48}=\right.$ $616, p<0.01)$. Post hoc analysis revealed that the growth rate of WJCs, based upon the cumulative population doublings per passage, was significantly fasterin $5 \%$ oxygen than in $21 \%$ oxygen. Post hoc testing showed that exposure to $5 \%$ oxygen accelerated growth from the first passage after exposure and this accelerated rate continued through passage 6 (see Fig. 2, middle panel). Population doubling time was significantly less when the cells were grown in 5\% oxygen, compared to cells grown in $21 \%$ oxygen: averaging $51 \mathrm{hrs}$ for cells grown in $5 \%$ oxygen versus $62 \mathrm{hrs}$ for cells grown $21 \%$ oxygen for passages $2-6$. In contrast, comparing the standard growth medium with $2 \%$ serum to SFM, growth rates were not different. The interaction term: Oxygen
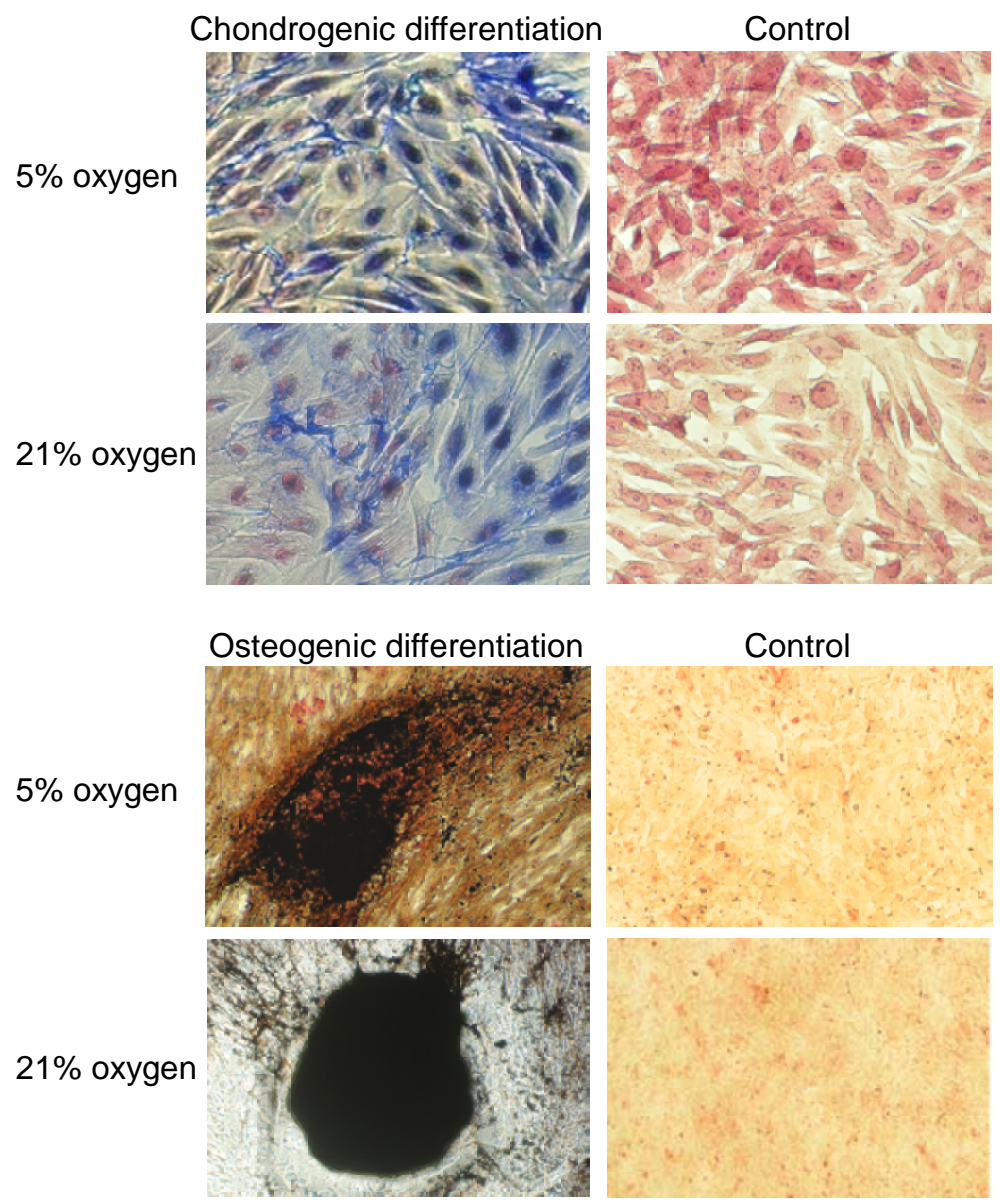

Fig. (1). Oxygen concentration did not modify osteogenic or chondrogenic differentiation of WJCs. WJCs at passage 4 were differentiated into cells of chondrogenic (top) or osteogenic lineage. TOP: WJCs culture in chondrogenic differentiation medium in culture (left), or WJCs maintained in control, undifferentiated conditions (right) for 21 days. Cartilage differentiation was seen by Mason's Trichrome staining for collagen fibers. BOTTOM: WJCs maintained in osteogenic medium (right) or control medium (left) for 21 days. The formation of mineralized matrix was revealed by von Kossa staining. Note that oxygen concentration at $5 \%$ or $21 \%$ during the culture and differentiation did not impact differentiation of Wharton's jelly-derived mesenchymal stromal cells (WJCs). 

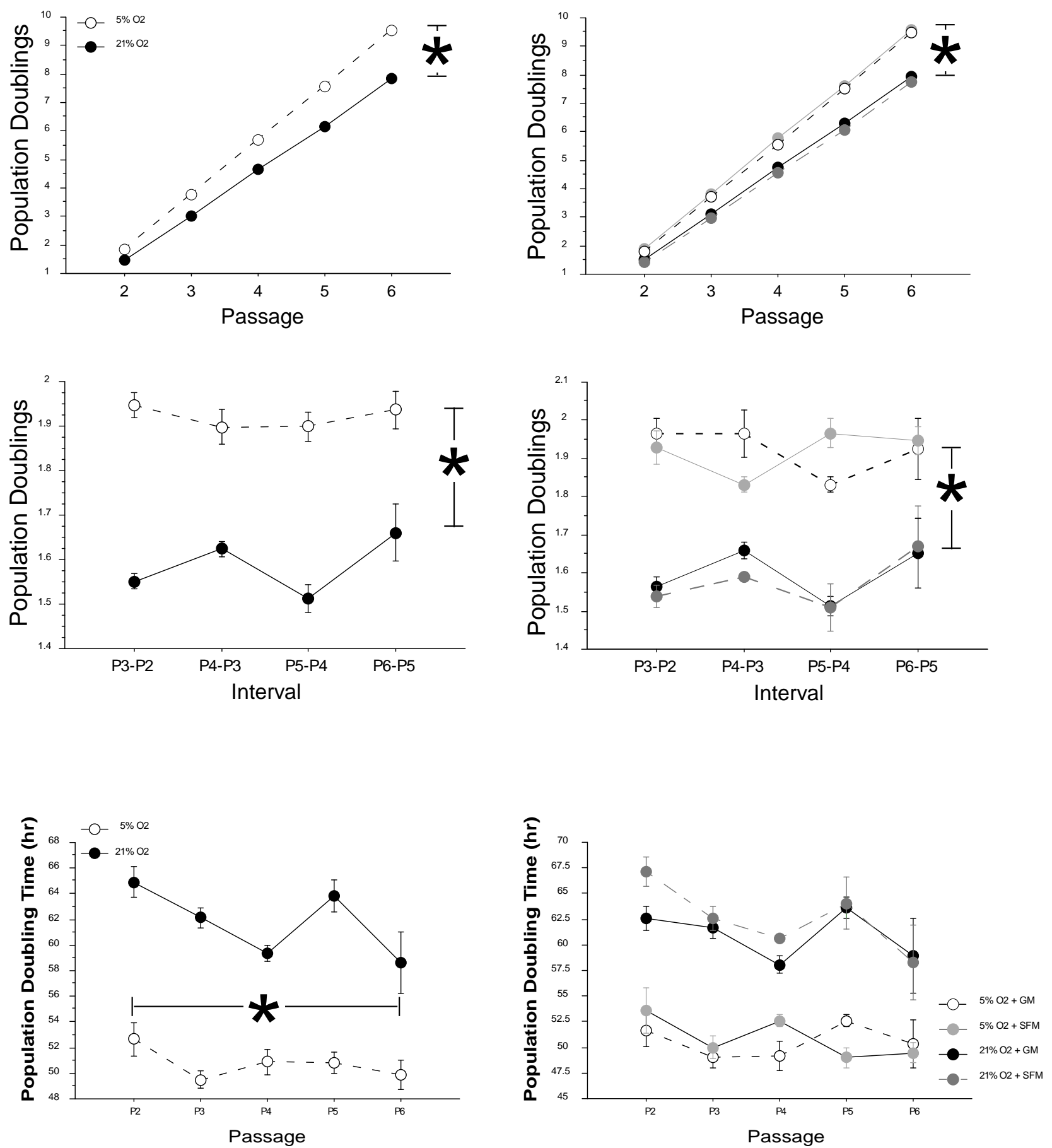

Fig. (2). Effect of oxygen concentration and composition of the medium on WJCs expansion on population doubling. TOP panel left: Cumulative population doublings. WJC cultured in $5 \%$ oxygen $\left(\right.$ low $\mathrm{O}_{2}$ ) grew faster than those grown in $21 \%$ oxygen (high $\left.\mathrm{O}_{2}\right)$, as indicated by greater number of cumulative population doublings. TOP panel right: There was no difference between the cumulative growth between our standard medium containing $2 \%$ serum and growth factors and serum-free medium. MIDDLE panel left: Population doublings at each passage. While WJCs were initially plated at the same density, ANOVA followed by post hoc analysis revealed that WJCs in 5\% oxygen grew faster from the first passage. MIDDLE panel right: There was no difference in WJC growth rate between the two media tested: Both serum-free medium (SFM) and our standard growth medium with $2 \%$ serum (SGM) grew faster in $5 \%$ oxygen than in $21 \%$ oxygen, as indicated by greater number of population doublings at each passage. BOTTOM panel left: Population doubling time over passage: WJCs increased their growth rate over passage. WJCs grown in $21 \%$ increased their growth rate more than WJCs grown in 5\% oxygen. Mean and standard error of the mean are plotted. Abbreviations: GM: growth medium with $2 \%$ serum; SFM: serum-free medium; $5 \% \mathrm{O}_{2}: 5 \%$ oxygen concentration; $21 \% \mathrm{O}_{2}: 21 \%$ oxygen concentration. 
concentration $\mathrm{x}$ Passage was significant $\left(\mathrm{F}_{4,48}=3.3\right.$, p < 0.05). Inspection of the growth curve (Fig. 2, top) and plotting population doubling time $v s$. passage (Fig. 2, bottom) indicated that growth rate increased with passage (doubling time decreased) in both oxygen concentrations. Cells grown in $21 \%$ oxygen decreased population doubling time from 65 hr at P1 to $59 \mathrm{hr}$ at P6, a $10 \%$ difference. In contrast, cells grown in $5 \%$ oxygen condition decreased their population doubling time from $53 \mathrm{hr}$ at P1 to $50 \mathrm{hr}$ at P6, about a $5 \%$ difference (Fig. 2, bottom). This may reflect adaptation to in vitro culture.

\section{Flow Cytometry}

Following expansion in two different oxygen concentrations and in two different growth media, surface marker expression was evaluated by flow cytometry. Using ANOVA, there were no effect on the expression of surface markers CD13, CD44, CD49e, CD90 and CD105. Representative data from one isolate is shown in Fig. (3): WJCs positively stained for CD13, CD44, CD49e, CD90 and CD105. A summary of the data from four isolates is provided in Table 1.

\section{Semi-Quantitative RT-PCR}

Hyaluronan synthase (HAS) activity isoforms I through III were evaluated because the WJCs synthesized hyaluronic acid (HA) and the WJCs express the receptor for HA, CD44. We hypothesized that HAS isoforms might be different between serum-free and the $2 \%$ serum enriched medium since HA plays a role in the mitogenic effect of PDGF-BB [27], and since HAS I gene expression is differentially regulated the BM-MSC of myeloma patients [28]. ANOVA revealed no significant main effects: Oxygen concentration or Medium, or interaction effects: Oxygen x Medium. There was a significant main effect: Passage $\left(\mathrm{F}_{1.24}=8.0, \mathrm{p}<0.05\right)$ and a significant interaction term: Gene $\mathrm{x}$ passage $\left(\mathrm{F}_{2.48}=\right.$ 9.5, $\mathrm{p}<0.05)$. These data are presented in Fig. (4). The expression of the pluripotency genes Oct4 and Nanog were

\section{$21 \%+\mathrm{GM}$}
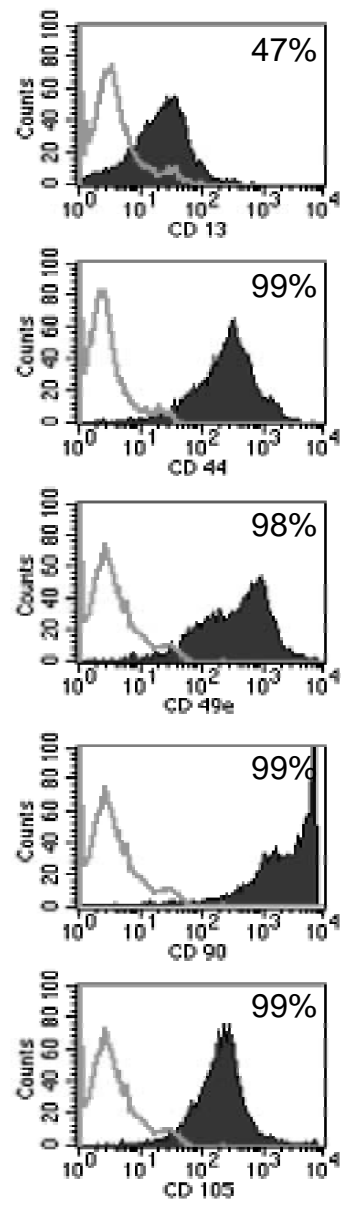
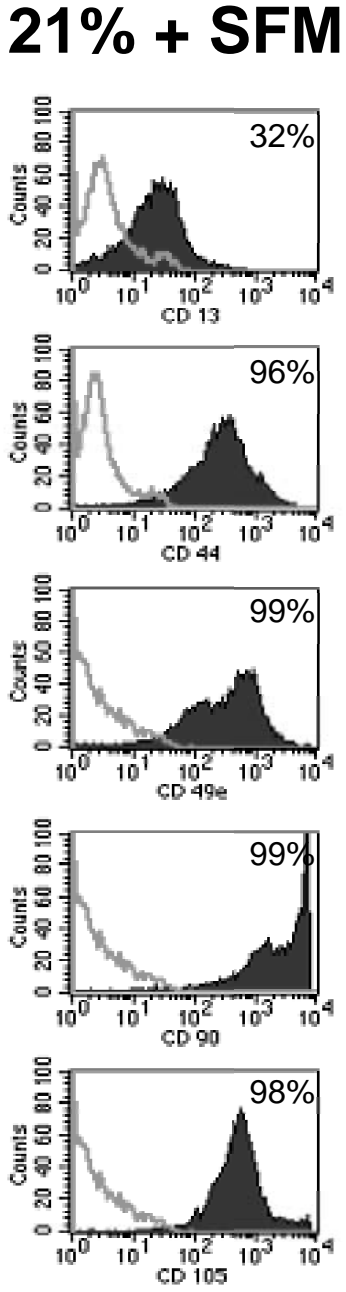

$5 \%+\mathrm{GM}$
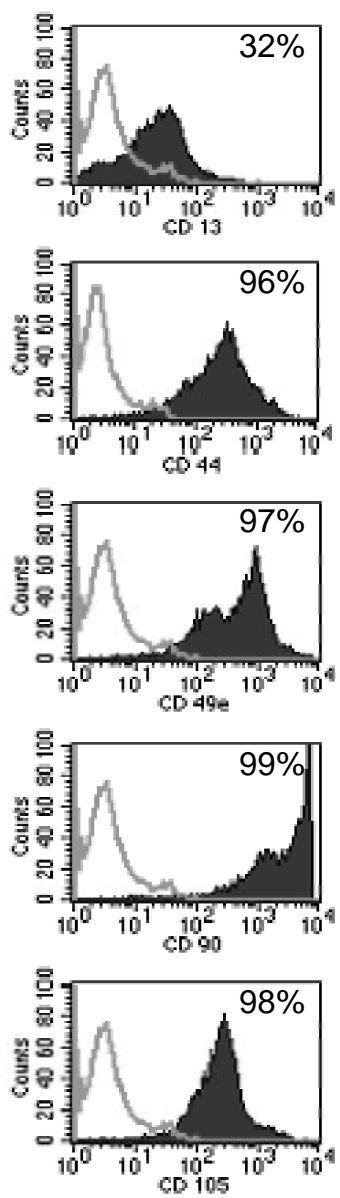
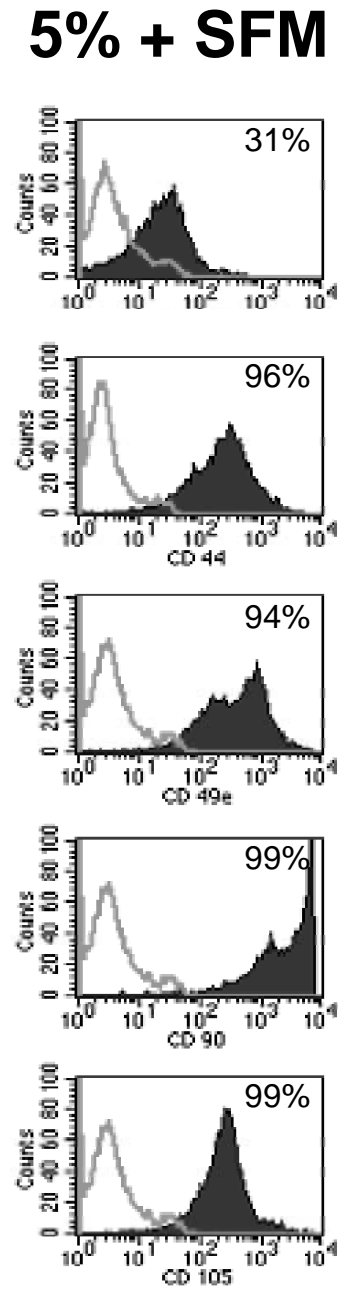

Fig. (3). Immunophenotyping profile of Wharton's jelly cells (WJCs) cultured in both $21 \%$ and $5 \% \mathrm{O}_{2}$ concentration using our standard growth medium with $2 \%$ serum (GM) and serum-free medium (SFM). Flow cytometry analysis of mesenchymal stromal cell (MSC) surface markers showed no changes in MSC-related surface markers by either 5\% or $21 \%$ oxygen concentration or between the two medium evaluated over 6 passages. Note: Data shown is representative of four isolates that were tested. Table 1 show averaged data for four isolates that were tested. The percentage shown in each histogram represents the $\%$ of positively stained cells in each histogram. 

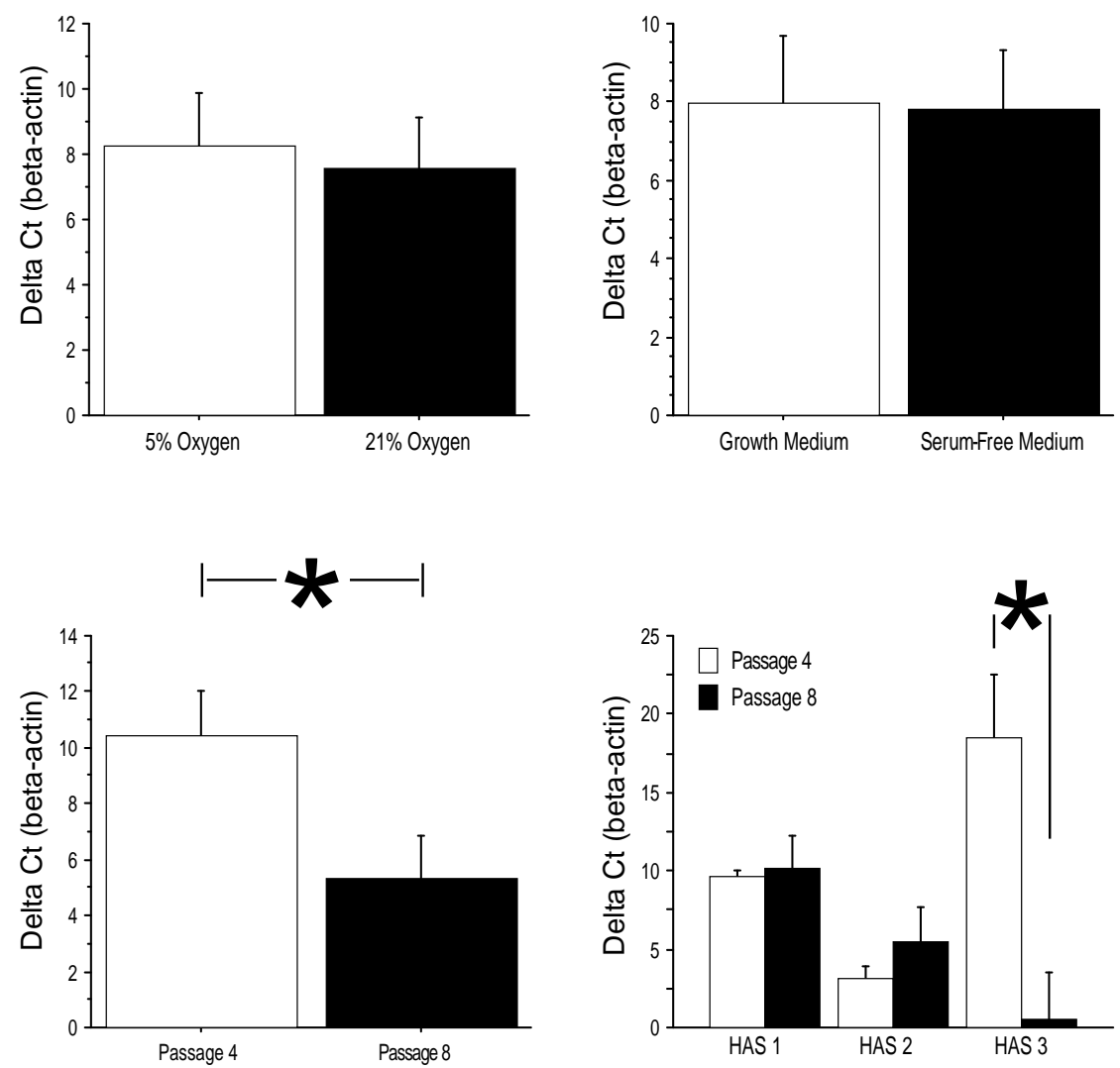

Fig. (4). Effect of Oxygen, Medium and Passage on HAS I, II, and II gene expression. TOP: Neither oxygen (left) nor medium (right) had an effect on HAS I, II, III gene expression. BOTTOM: Passage had a significant effect (left) and there was a significant interaction term: Gene $\mathrm{x}$ passage, which resulted from a significant change in HAS III gene expression between passage 4 and 8 (bottom right panel). Delta Ct values are shown using beta-actin as the control gene. Data shown are averaged from duplicates or triplicates. The average and one standard error of the mean are graphed.
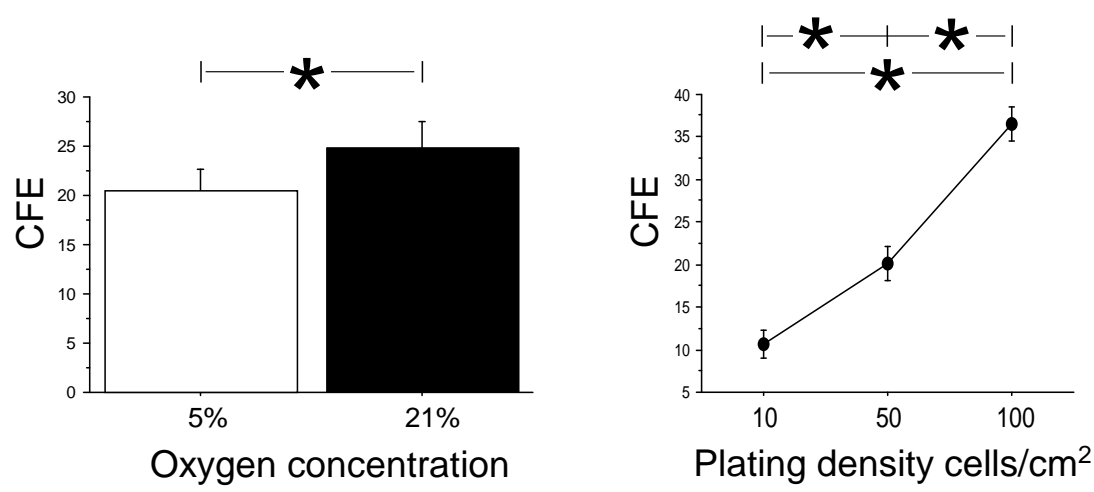

Fig. (5). Effect of oxygen concentration or plating density on Colony Forming Efficiency (CFE). The colony forming efficiency (CFE) was defined as the ratio of the number of Wharton's jelly cells (WJCs) per observed colonies. Left: Overall, CFE was significantly higher when WJCs were cultured in 5\% oxygen concentration. Right: Overall, CFE was significantly greater at lower initial plating density. The lowest density used here $\left(10\right.$ cells $\left./ \mathrm{cm}^{2}\right)$ had higher CFE than CFE at either 50 or 100 cells $/ \mathrm{cm}^{2}$ plating density. Mean and standard error of the mean are plotted. Abbreviations: CFE: colony forming efficiency.

evaluated, too. Neither Oct4 nor Nanog was expressed in WJCs. In contrast, Oct4 and Nanog were expressed in NT2 positive control cells (data not shown).

\section{Project 2: Effect of Oxygen Concentration and Plating Density on CFE}

Each WJC isolate was divided between three plating density groups $\left(10,50\right.$ and 100 cells $\left./ \mathrm{cm}^{2}\right)$ and 2 oxygen tension groups $(21 \%$ and $5 \%)$ and grown from passage 1 through passage 5. CFU-F was assessed at each passage. The observed CFU-F was normalized to account for different plating density by dividing by the number of WJCs plated to generate colony forming efficiency (CFE) statistic. ANOVA revealed significant main effects: Plating density $\left(\mathrm{F}_{2.83}=\right.$ $37.4, \mathrm{p}<0.01)$ and Oxygen concentration $\left(\mathrm{F}_{1,83}=5.8\right.$, $\mathrm{p}<0.05)$, and a significant interaction term oxygen concentration $x$ passage $\left(\mathrm{F}_{4.83}=2.8, \mathrm{p}<0.05\right)$. 
As shown in Fig. (5), overall CFE was improved from an average of $25.2 \pm 2.1$ WJCs to produce one CFU-F in $21 \%$ oxygen to $19.9 \pm 1.6$ by incubation in $5 \%$ oxygen, a $21 \%$ improvement. Similarly post hoc analysis showed that lowering the density of the cells improved CFE: 10 cells/ $\mathrm{cm}^{2}$ produced significantly higher CFE than 50 or 100 cells/ $\mathrm{cm}^{2}$ : CFE improved significantly from an average of $36.5 \pm$ $2.1 \mathrm{WJCs}$ to produce one CFU-F at 100 cells $/ \mathrm{cm}^{2}$, to $20.0 \pm$ 2.0 at 50 cells $/ \mathrm{cm}^{2}$, to $10.6 \pm 1.7$ at 10 cells $/ \mathrm{cm}^{2}$, see Fig. (5). Post hoc analysis of the interaction between oxygen concentration and passage revealed that maintaining WJCs in 5\% oxygen maintained CFE; however, expansion in $21 \%$ oxygen resulted in maintaining CFE at passage 1-4 and significant decrease CFE at passage 5 (see Fig. 6).

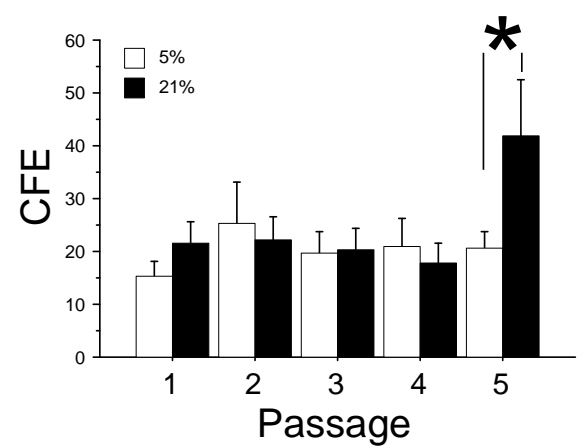

Fig. (6). Interaction between Colony Forming Efficiency (CFE) and passage. CFE was not significantly different when Wharton's jelly cells are grown in the two different oxygen concentrations from passage 1 through 4 . At passage 5, however, WJCs grown $21 \%$ oxygen had lower CFE than WJCs grown in 5\% oxygen. Mean and standard error of the mean are plotted. Abbreviations: CFE: colony forming efficiency; $5 \% \quad \mathrm{O}_{2}: 5 \%$ oxygen concentration; $21 \% \quad \mathrm{O}_{2}$ : $21 \%$ oxygen concentration.
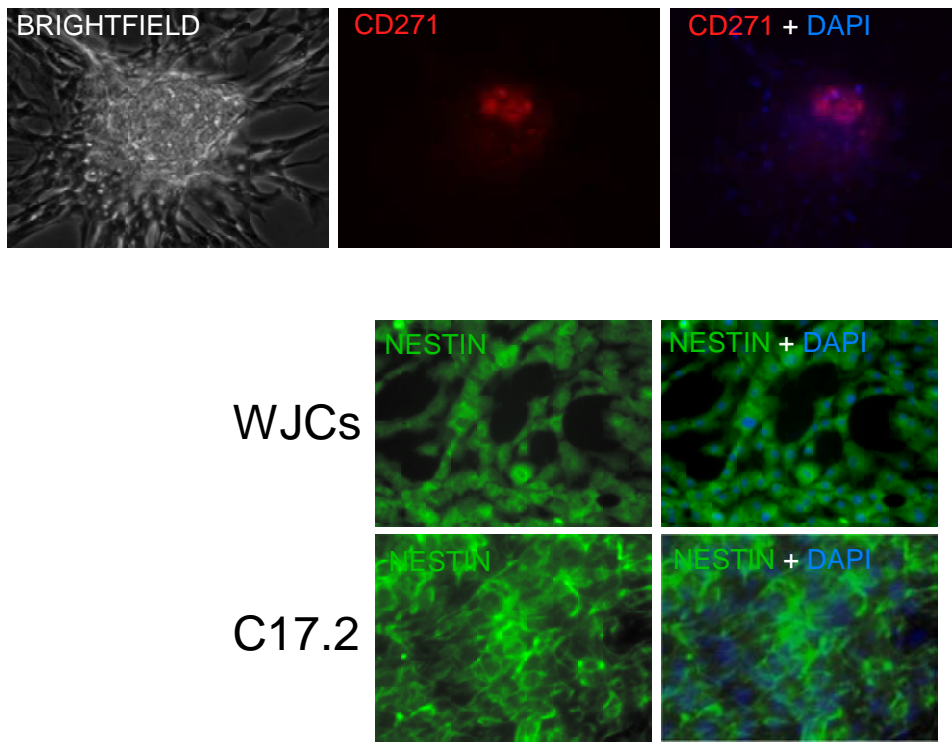

\section{Colony Size}

There was no difference in the colony size measurements between the two investigators and their colony size measurements were pooled. From ANOVA, the main effect: Plating density was significant $\left(\mathrm{F}_{1.567}=9.29, \mathrm{p}<0.01\right)$ and the main effect: Oyxgen concentration missed significance $\left(\mathrm{F}_{1.567}=3.32, \mathrm{p}=0.07\right.$, two tailed $)$ and the interaction term: Plating density $\mathrm{x}$ oxygen concentration was not significant $\left(\mathrm{F}_{1.567}=0.05, \mathrm{p}>0.05\right)$. Post hoc analysis revealed that the colonies in the 50 cells/ $\mathrm{cm}^{2}$ condition were significantly larger than colonies in the 10 cells/ $\mathrm{cm}^{2}$ condition by $8 \%$ $\left(25.16 \pm 0.48\right.$ for 10 cells $/ \mathrm{cm}^{2}$ vs. $27.49 \pm 0.56$ for 50 cells per $\left.\mathrm{cm}^{2}\right)$.

\section{Wharton's Jelly CD271 Positive Cells are Restricted to Colonies}

As shown at the top of Fig. (7), colonies derived from WJCs were analyzed by immunofluorescence. We observed CD271-positive cells within a subset of cells within colonies and not elsewhere. In contrast, as shown at the bottom of Fig. (7), nestin-positive cells were found in colonies and in the cells that did not form colonies in WJC cultures.

\section{Telomerase Activity}

The TRAP assay was run in triplicates on WJCs at passage 3 in two independent experiments: WJCs exposed to $5 \%$ oxygen or $21 \%$ oxygen for three passages (long term culture) or WJCs exposed to $5 \%$ or $21 \%$ oxygen for one passage (two passages at $21 \%$ and then moved to $5 \%$ oxygen for one passage, short term culture) or heat-inactivated cells (WJCs and rat undifferentiated embryonic stem cells as a negative control) and undifferentiated rat embryonic stem cells as positive control (supplied by James Hong). The $\Delta$

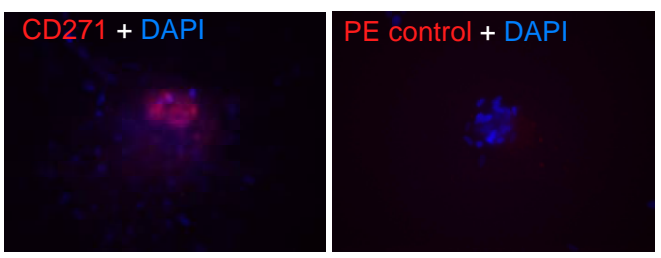

Fig. (7). Immunocytochemistry of Wharton's jelly cells. TOP: CD271 immunofluorescence staining of Wharton's jelly cells (WJCs). Left panel: Phase contrast micrograph of Wharton's jelly cells in culture. Second panel from left: CD271 immunofluorescence detected with PE (red). Positively stained CD271 cells were only found in a portion of the core of each colony and not elsewhere. Third panel from left: Combination of CD271 staining shown in red with nuclear staining by DAPI shown in blue. Right panel: Negative control made by staining with the PE isotype control antibody only. Bottom: Nestin immunofluorescence staining of WJCs (Top) and positive control (immortalized mouse neural progenitor cells, C17.2, bottom). Note that, in contrast to CD271 where only a sub-population of WJCs in colonies is stained, virtually all WJCs were stained by nestin, including colonies. Calibration bar $=500$ micrometers. 
Continuous exposure to either 5 or $21 \%$ oxygen at P3

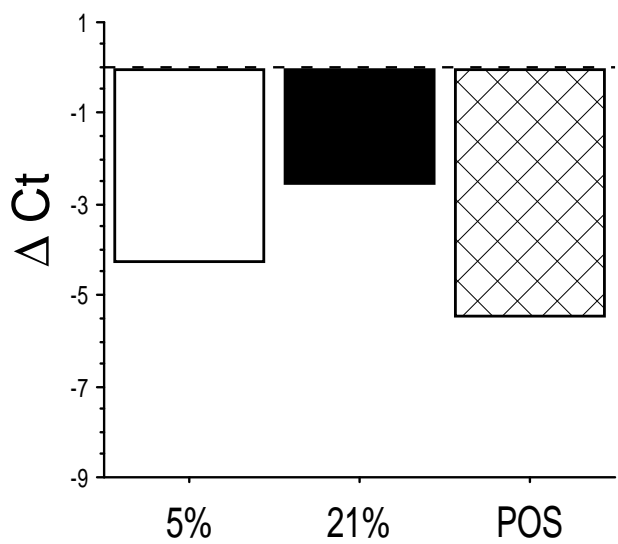

3 day exposure

to $5 \%$ oxygen at P3

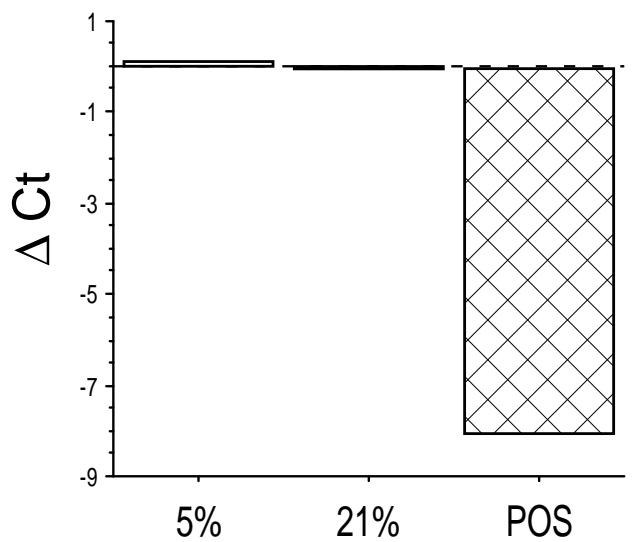

Fig. (8). Effect of short-term versus long-term exposure to either 5\% oxygen or $21 \%$ oxygen on telomerase expression. TRAP assay was used to measure telomerase activity, each point was run in triplicate and averaged. This is representative data from two independent trials. LEFT panel: Long-term culture (3 passages) in either 5\% oxygen concentration or $21 \%$ oxygen concentration (measurements made at passage 3). The Wharton's jelly cells (WJCs) exposed to 5\% oxygen had higher telomerase expression than WJCs cultured in $21 \%$ oxygen. The positive control (POS) is telomerase expression by rat embryonic stem cells (supplied by James Hong). RIGHT panel: Short-term culture ( 1 passage) in either $5 \%$ oxygen concentration or $21 \%$ oxygen concentration (measurements made at passage 3 ). There was no change in telomerase expression when cells are moved from $21 \%$ to $5 \%$ oxygen for one passage only.

threshold count $(\Delta \mathrm{Ct})$ values were calculated by subtracting the average $\mathrm{Ct}$ for heat-inactivated cells. TRAP assay was run on two independent experiments and the results are shown in Fig. (8). Note that no statistical analysis was conducted on this pilot data. TRAP assay revealed that WJCat passage 3 which were grown in 5\% oxygen for three passages (long-term culture) had apparently higher telomerase expression than WJCs grown in $21 \%$ oxygen (left panel in Fig. 8). In contrast, WJCs at passage 3 which were grown in $21 \%$ oxygen for 2 passages and moved to $5 \%$ for the last passage (short-term culture) had apparently the same amount of telomerase as WJCs grown in $21 \%$ (right panel in Fig. 8). Heat inactivation significantly reduced telomerase expression (data not shown) and rat undifferentiated embryonic stem cells had high telomerase expression (labeled as positive control, POS, in Fig. 8).

\section{DISCUSSION}

Here, the effects of oxygen concentration, plating density, passage, and culture medium were examined on Wharton's jelly-derived MSCs (WJCs). Oxygen concentration and plating density had potent effects on WJC expansion which was indicated by differences in population doubling time and CFE. There was no effect of growth in serum-free medium when it was compared to our standard growth medium which contains $2 \%$ serum, growth factors and cytokines [14]. We hypothesized that reduced oxygen concentration during culture would increase WJC expansion rates and CFE since previous work had shown that reduced oxygen concentration during culture has potent effects on expansion of bone marrow-derived MSCs [29-35] and WJCs [36,37]. We speculated that plating density would impact WJC expansion based upon previous work using bone marrow-derived MSCs which had shown that MSC have more rapid expansion after plating a low density [38]. Additionally, our work fits with previous work where WJCs were plated at extremely low density $(<$ one cell per well) and very high CFE of 1 colony per 3-4 WJCs [17]. Together our work suggests that the parameters: oxygen concentration and plating density have a great impact on WJC expansion and CFE and that use of serum-free medium did not affect expansion rate.

With regards to oxygen concentration during expansion, our results show that $5 \%$ oxygen concentration increases the growth rate and improves CFE compared to $21 \%$ oxygen. The effect on growth rate was significant from the first passage and continues throughout the first five passages, and lowered oxygen concentration improved CFE of WJCs. These findings suggest two things. First, that the physiological effects of oxygen occur within the first days of culture and are maintained for at least five passages, and second that lowered oxygen concentration improves CFE. In this regard, our results using WJCs are consistent with the effect of oxygen concentration on bone marrow MSCs [31]. In a previous report, Lavrentieva et al., compare the effect of $1.5,2.5,5 \%$ oxygen to $21 \%$ oxygen exposure for $72 \mathrm{hrs}$ on growth of WJCs [36]. They found that $72 \mathrm{hrs}$ of exposure to $2.5 \%$ oxygen concentration had a significant enhancement of growth compared to $21 \%$ oxygen, and $5 \%$ oxygen showed a trend to increase cell number that was not significant. The increased growth was correlated with an increase in hypoxiainducible factor 1 alpha. A second group, Farias et al., reported that WJCs culture in $5 \%$ oxygen concentration maintained higher $\mathrm{CFE}$ and greater overall growth compared to $21 \%$ oxygen [39]. In contrast, another group reported that reduced oxygen $(2 \%)$ enhanced proliferation rate of WJCs, but the enhancement required exposure of WJCs for five passages before reaching statistical significance [37]. Our lab was the first to show that $5 \%$ oxygen concentration affects both cell expansion rate and CFU-F from the first passage. We found that the effect of oxygen concentration was on expansion rate and CFE was maintained for at least four passages. Thus, our data is supported by previous reports and 
extends previous work on WJCs maintained in < $21 \%$ oxygen concentration culture conditions [39,37]. Additionally, we report that the interaction term: oxygen concentration $\mathrm{x}$ passage was significant. We found that CFE was consistent over passage when WJCs were cultured in 5\% oxygen for passages $1-5$. In contrast, WJCs cultured in $21 \%$ oxygen, CFE decreased at passage 5. To our knowledge, this is the first report of significant interaction between oxygen concentration and passage, Farias et al., observed loss of CFE in WJCs maintained for 37 days in culture at $21 \%$ oxygen, while CFE was maintained at a stable level in 5\% oxygen.

Oxygen concentration has broad physiological effect and affects many cell types. For example, reduction in oxygen concentration enhances reprogramming efficiency of diploid cells towards induced pluripotent stem cells [40], and may have a role in stabilizing the genome during replication to prevent aging effects (see review by [41]). The observed effect of reducing oxygen concentration on CFE and expansion rate are accompanied by induction of hypoxia inducible factors (HIFs) in a variety of cell lines [42-44] and in WJCs [36], however the exact mechanism(s) responsible for the observed effects on proliferation are not clear. For example, it is not clear whether HIF or other effects of reduced oxygen promotes faster expansion.

Transduction of telomerase is one method to immortalize cells and has been previously shown to affect population doubling time $[45,46]$. Previously, our group reported that telomerase is expressed in WJCs [47] and other groups have linked lowered oxygen tension culture with enhanced telomerase activity and delayed replicative senescence [4850]. In the pilot study reported here, enhanced telomerase activity was observed in WJCs at passage 3 that were cultured in 5\% oxygen compared to $21 \%$ oxygen for passages 1-3. In contrast, WJCs which were grown in $21 \%$ oxygen and moved to $5 \%$ for passage 2->3 did not demonstrate increased telomerase activity. These observations suggest that enhanced telomerase may be associated with the decrease in population doubling time that is found with culture adaptation, and that telomerase is not likely to be responsible for the initial increase in growth rate observed at first passage.

The role of reactive oxygen species in DNA damage has been previously reviewed [41,51]. One possible mechanism underlying these findings is DNA damage/ telomere shortening by reactive oxygen in the $21 \%$ oxygen concentration condition. Therefore, it is possible that oxidative stress may be mitigated by including antioxidants in the medium such as vitamin $\mathrm{C}$ or beta mercaptoethanol, etc, or by using lower glucose concentration to reduce metabolic reactive oxygen, if one did not have access to a $\mathrm{CO}_{2}$ and $\mathrm{O}_{2}$ regulated incubator.

While reducing oxygen concentration from $21 \%$ to $5 \%$ enhanced growth rate and CFE, we did not observe an effect on HAS isoforms I, II or III, or on Oct4 or Nanog gene expression, osteogenic or chondrogenic differentiation capacity or MSC surface marker expression. Similarly, work from Nekanti et al., reported that reducing oxygen concentration to $2 \%$ did not change Oct4 expression, osteogenic or chondrogenic differentiation capacity or influence surface marker expression [37]. In contrast, work from Ren et al. indicated that culturing bone marrow MSCs under 8\% oxygen tension increased proliferation rate (and increased the percentage of cells in S and G2/M phase of cell cycle), decreased Oct 4 expression, modified surface marker expression for CD44 and CD13, and enhanced differentiation of MSCs [52]. Thus, WJCs may have a different physiological response to reduced oxygen concentration culture compared to bone marrow MSCs. These differences in differentiation capacity of MSCs from bone marrow $v s$. Wharton's jelly may impact their use for certain clinical applications, such as using MSCs in tissue engineering or for repair of bony defects. It is not clear from the present work whether reduced oxygen concentration during expansion affects other properties of MSCs, such as immunophysiology or cytokine production. Therefore, it is unknown whether reduced oxygen concentration during expansion would impact MSC's use in treatment of graft versus host disease (GVHD), for example:

A second variable examined here was plating density. We showed that lowering plating density from 100 cells $/ \mathrm{cm}^{2}$ to 10 cells $/ \mathrm{cm}^{2}$ increased the CFE of WJCs. This finding is consistent with what has been reported for bone marrowderived MSCs [53]. Using bone marrow MSCs, Sotiropoulou $e$ al., found that reducing plating density from 5,000 cells $/ \mathrm{cm}^{2}$ to 50 cells $/ \mathrm{cm}^{2}$ had a huge impact on proliferation and growth index [53]. Nekanti et al. evaluated the effect of plating density on expansion rate in an attempt to optimize expansion of WJCs [54]. They found that the lowest density they evaluated $\left(1000\right.$ cells $\left./ \mathrm{cm}^{2}\right)$ had the fastest proliferation rate and that the proliferation rate decreased in a density-dependent fashion (slowest proliferation rate at their highest density, $5000 \mathrm{cells} / \mathrm{cm}^{2}$ ). While we did not correlated proliferation rate and plating density, the clonogenicity of MSCs and, thus, CFE, is directly correlated with proliferation rate. Therefore, our findings of increased CFE with decreasing plating density are in agreement with the expansion data of Nekanti et al.

While the effect of plating density on CFU-F has not been systematically evaluated in WJCs till date, the work of JE Davies lab [17,55] supports the notion that reducing plating density enhances CFE in WJCs. Sarugaser et al. reported that at passage 0,1 colony in their CFU-F assay was found in 333 plated WJCs and that more CFU-F were found at higher density, suggesting a paracrine effect enabling clonogencity of WJCs [55]. In a follow-up paper, the Davies' lab reported finding 1 CFU-F for 3-4 for WJCs, when WJCs were plated at the ultra-low density of 1 to 0.2 cells per well [17]. While this finding contradicts their earlier report that CFU-F increased with plating density, the observed frequency of CFU-F is consistent with the frequency observed here (1 CFU per $10 \mathrm{WJCs})$. In contrast to what has been reported for WJCs here and for bone marrow-derived MSCs (cited above), plating density was not a critical variable in adipose-derived MSCs [56]. The mechanism(s) or factors underlying the plating density effect are not known. At higher plating density, paracrine signaling or metabolic products may down-regulate MSCs selfrenewal and affect clonogenic frequency. We also found that plating density affects colony size: colonies were significantly larger when the WJCs were plated at $50 \mathrm{cell} / \mathrm{cm}^{2}$ density compared to 10 cells $/ \mathrm{cm}^{2}$. This finding fits with a previous observation from bone marrow-derived MSCs where the small, round cells observed at low plating density 
were found to be the rapidly renewing subpopulation [57, 58]. Our data suggests that plating density has two effects: first, lower plating density increases the percentage of smaller cells and, second, decreasing plating density increases $\mathrm{CFE}$ by enhancing proliferation rate.

We found that culturing WJCs at $5 \%$ oxygen concentration and at a density of 10 cells $/ \mathrm{cm}^{2}$ were optimal conditions to maintain CFE and producing maximal proliferation rate. Cell number is one aspect to consider for cellular therapy. Others have suggested that lower oxygen concentration during expansion may improve MSC cell therapy products. For example, work by Liu showed that brief hypoxic exposure improved MSCs for cellular mobilization and homing function by up-regulation of SDF-1 CXCR4 mediated homing [59]. Ren et al., reported that reduced oxygen concentration enables differentiation of MSC [52]. Others reported diametrically different results [48]. Therefore, it is likely that standard operating procedures (SOP) will need to be optimized for each MSC tissue source and clinical application.

We did not find a significant interaction: Plating density $x$ oxygen concentration. It is worth noting that maximal CFE was found at the lowest plating density $\left(10\right.$ cells $\left./ \mathrm{cm}^{2}\right)$ in $5 \%$ oxygen conditions. In the context of optimizing production of cells for clinical use, our data suggest that combination of reduced plating density and expansion in 5\% oxygen concentration would be optimal for maintain $\mathrm{CFE}$ and maximizing WJC expansion rate.

The third variable examined was medium components. Specifically, we compared the growth rate of WJCs expanded in our standard growth medium that contains $2 \%$ serum and growth factor with a serum-free medium formation containing bFGF that was previously described [25]. We found no differences in growth rate between the two medium formulations over 6 passages of expansion. Animal serum is considered as a potential problem in clinical trials as patients may generate antibodies against serum protein that remain on cells that have been expanded in animal serum [60,61]. Furthermore, many laboratories use selected lots of serum since serum lot is an important variable in MSC expansion $[62,63]$. Since lot selection is time consuming and a potential limitation for clinical use of MSCs, SOP that eliminates animal serum would be advantageous for MSCs. Therefore, limiting or excluding animal serum for expansion of cells destined for cellular therapy has been an important consideration [64]. Here, we report that using serum-free medium did not impact expansion of WJCs. The major limitation of using serum-free medium is the requirement to coat plates with $0.1 \%$ gelatin or other special plate coatings to insure good adherence and expansion in serum-free medium. This limitation impacted the present report, since we did not examine the effect of serum-free medium on CFE or differentiation, since we were concerned that introducing a different ECM would confound our comparison further. The question of whether serum-free medium impacts differentiation was not addressed here and should be addressed in the future before MSCs expanded in SFM can be considered for clinical trials.

As recently reviewed by Bianco et al., identification of the stem cell subpopulation within MSC cultures is elusive
[65]. The two properties of MSC stem cells that can be evaluated in vitro are self-renewal and differentiation. To demonstrate these stem cell properties, self-renewal is measured by the CFU-F assay and MSCs may be differentiated into specialized cells of the mesodermal lineages, such as chondrogenic or osteogenic lineages. Since these properties are expressed in vitro assays, they may not accurately represent the number of MSC stem cells in vivo. As reviewed by Bianco et al., no markers distinguish multipotent MSC stem cells from more committed and less potent progenitor MSCs. Clonogenic MSCs can be enriched prospectively by certain surface markers such as STRO-1 [66], MCAM/CD146 [67] or CD56, CD105, CD140b, CD271, CD349, etc. $[25,68,69]$. Here, WJCs in the colonies were shown to express CD271. Other work suggests that MSC stem cells in bone marrow are nestin-positive e.g., [7072]. In previous work, our group [73] and others [74] have shown that nestin is expressed by a population of undifferentiated WJCS. The percentage of WJCs that express nestin decreases with differentiation [73]. In pilot work shown here, we found that nestin co-localizes with CD271positive cells in WJC colonies. The results presented here and our pilot work would agree with previous reports that show that bone marrow-derived MSCs expressing CD271 together with CD140b or CD105 may enriched for CFU-F.

Telomerase has a role in cell proliferation and maintaining long telomeres. Recent work has shown that reduced oxygen concentration during culture up-regulates telomerase in stem cells $[74,75]$. Other work has shown that telomerase may increase cell proliferation rate [76]. Here, we showed higher levels of telomerase expression in WJCs exposed to $5 \%$ oxygen for three passages, which correlates with increased cell proliferation rate and CFE. Previously, it was shown that WJCs express telomerase [47] and can maintain long telomeres up to 15 passages [74]. Therefore, it is likely that reducing oxygen concentration in culture up-regulates hypoxia inducible factors (HIFs) and downstream effects from HIF activation include increased cell proliferation and maintenance of $\mathrm{CFU}-\mathrm{F}$, perhaps by affecting telomerase. Further work is needed to demonstrate that lower oxygen concentration in culture maintains the number of stem cells in MSC cultures.

This study revealed that oxygen concentration and plating density affect several biological properties of WJCs. Reduction of oxygen concentration enhanced expansion rate and CFE, without observable impact on WJC surface markers expression, differentiation to bone or cartilage, or HAS, Nanog or Oct4 gene expression. We did not find any interaction or additive effect of oxygen or plating density. These results suggest that these two variables can optimized to produce an SOP for generation of WJCs for tissue engineering or cellular therapy.

\section{CONTRIBUTIONS}

YL and KS conducted the experiments, assembled the data and assisted with data analysis and wrote parts of the paper, ET and JC assisted with the experiments. MLW designed experiments, analyzed the data, made the final figures, and wrote the paper. 


\section{ACKNOWLEDGEMENTS}

Dr. Suzanne Bennett and The Women's Health Group are thanked for assisting our research. The authors acknowledge support from NIH NS-34160 to MLW as well as support from the KSU Terry C. Johnson Center for Basic Cancer Research. KS generated and reported the data presented in Project 1 for his Masters project. YL was supported by the KSU graduate school travel stipend, the Jane Westfall Graduate Travel Award for Women, and received financial support from Venezuela. ET received support from the KSU Bridges Program, the Terry C. Johnson Center for Basic Cancer Research and the KSU Developing Scholar program. The authors thank the other members of the Weiss lab for their support and assistance. MLW acknowledges the unflagging support of BGW.

\section{CONFLICT OF INTEREST}

None decleard.

\section{REFERENCE}

[1] Dominici M, Le Blanc K, Mueller I, et al. Minimal criteria for defining multipotent mesenchymal stromal cells. The International Society for Cellular Therapy position statement. Cytotherapy 2006; 8: 315-7.

[2] da Silva ML, Chagastelles PC, Nardi NB. Mesenchymal stem cells reside in virtually all post-natal organs and tissues. J Cell Sci 2006; 119: 2204-13.

[3] Uccelli A, Moretta L, Pistoia V. Mesenchymal stem cells in health and disease. Nat Rev Immunol 2008; 8: 726-36.

[4] Villarruel SM, Boehm CA, Pennington M, et al. The effect of oxygen tension on the in vitro assay of human osteoblastic connective tissue progenitor cells. J Orthop Res 2008; 26: 1390-7.

[5] Koc ON, Lazarus HM. Mesenchymal stem cells: heading into the clinic. Bone Marrow Transplant 2001; 27: 235-9.

[6] Satija NK, Singh VK, Verma YK, et al. Mesenchymal stem cellbased therapy: a new paradigm in regenerative medicine. J Cell Mol Med 2009; 13: 4385-402.

[7] Kang S, Yang YJ, Li CJ, Gao RL. Effects of intracoronary autologous bone marrow cells on left ventricular function in acute myocardial infarction: a systematic review and meta-analysis for randomized controlled trials. Coron Artery Dis 2008; 19: 327-35.

[8] Wagner W, Ho AD. Mesenchymal stem cell preparations-comparing apples and oranges. Stem Cell Rev 2007; 3: 239-48.

[9] Wang Z, Song J, Taichman RS, Krebsbach PH. Ablation of proliferating marrow with 5-fluorouracil allows partial purification of mesenchymal stem cells. Stem Cells 2006; 24: 1573-82.

[10] Assmus B, Fischer-Rasokat U, Honold J, et al. Transcoronary transplantation of functionally competent BMCs is associated with a decrease in natriuretic peptide serum levels and improved survival of patients with chronic postinfarction heart failure: results of the TOPCARE-CHD Registry. Circ Res 2007; 100: 1234-41.

[11] Clarke E, McCann SR. Age dependent in vitro stromal growth. Bone Marrow Transplant 1989; 4: 596-7.

[12] Dzau VJ, Gnecchi M, Pachori AS, Morello F, Melo LG. Therapeutic potential of endothelial progenitor cells in cardiovascular diseases. Hypertension 2005; 46: 7-18.

[13] Heeschen C, Lehmann R, Honold J, et al. Profoundly reduced neovascularization capacity of bone marrow mononuclear cells derived from patients with chronic ischemic heart disease. Circulation 2004; 109: 1615-22.

[14] Seshareddy K, Troyer D, Weiss ML. Method to isolate mesenchymal-like cells from Wharton's Jelly of umbilical cord. Methods Cell Biol 2008; 86: 101-19.

[15] Baksh D, Yao R, Tuan RS. Comparison of proliferative and multilineage differentiation potential of human mesenchymal stem cells derived from umbilical cord and bone marrow. Stem Cells 2007; 25: 1384-92.
[16] Lund RD, Wang S, Lu B, et al. Cells isolated from umbilical cord tissue rescue photoreceptors and visual functions in a rodent model of retinal disease. Stem Cells 2007; 25: 602-11.

[17] Sarugaser R, Hanoun L, Keating A, Stanford WL, Davies JE. Human mesenchymal stem cells self-renew and differentiate according to a deterministic hierarchy. PLoS One 2009; 4: e6498-

[18] Deuse T, Stubbendorff M, Tang-Quan K, et al. Immunogenicity and immunomodulatory properties of umbilical cord lining mesenchymal stem cells. Cell Transplant 2010; [Epub ahead of print].

[19] Najar M, Raicevic G, Boufker HI, et al. Mesenchymal stromal cells use PGE2 to modulate activation and proliferation of lymphocyte subsets: Combined comparison of adipose tissue, Wharton's Jelly and bone marrow sources. Cell Immunol 2010; 264: 171-9.

[20] Prasanna SJ, Gopalakrishnan D, Shankar SR, Vasandan AB. Proinflammatory cytokines, IFNgamma and TNFalpha, influence immune properties of human bone marrow and Wharton jelly mesenchymal stem cells differentially. PLoS One 2010; 5: e9016.

[21] Weiss ML, Anderson C, Medicetty S, et al. Immune properties of human umbilical cord Wharton's jelly-derived cells. Stem Cells 2008; 26: 2865-74

[22] Yoo KH, Jang IK, Lee MW, et al. Comparison of immunomodulatory properties of mesenchymal stem cells derived from adult human tissues. Cell Immunol 2009; 259: 150-6.

[23] Zeddou M, Briquet A, Relic B, et al. The umbilical cord matrix is a better source of mesenchymal stem cells (MSC) than the umbilical cord blood. Cell Biol Int 2010; 34: 693-701.

[24] Zhou H, Guo M, Bian C, et al. Efficacy of bone marrow-derived mesenchymal stem cells in the treatment of sclerodermatous chronic graft-versus-host disease: clinical report. Biol Blood Marrow Transplant 2010; 16: 403-12.

[25] Battula VL, Bareiss PM, Treml S, et al. Human placenta and bone marrow derived MSC cultured in serum-free, b-FGF-containing medium express cell surface frizzled-9 and SSEA-4 and give rise to multilineage differentiation. Differentiation 2007; 75: 279-91

[26] Lu LL, Liu YJ, Yang SG, et al. Isolation and characterization of human umbilical cord mesenchymal stem cells with hematopoiesissupportive function and other potentials. Haematologica 2006; 91: 1017-26.

[27] Li L, Asteriou T, Bernert B, Heldin CH, Heldin P. Growth factor regulation of hyaluronan synthesis and degradation in human dermal fibroblasts: importance of hyaluronan for the mitogenic response of PDGF-BB. Biochem J 2007; 404: 327-36.

[28] Calabro A, Oken MM, Hascall VC, Masellis AM. Characterization of hyaluronan synthase expression and hyaluronan synthesis in bone marrow mesenchymal progenitor cells: predominant expression of HAS1 mRNA and up-regulated hyaluronan synthesis in bone marrow cells derived from multiple myeloma patients. Blood 2002; 100: 2578-85.

[29] Basciano L, Nemos C, Foliguet B, et al. Long term culture of mesenchymal stem cells in hypoxia promotes a genetic program maintaining their undifferentiated and multipotent status. BMC Cell Biol 2011; 12: 12

[30] Carrancio S, Lopez-Holgado N, Sanchez-Guijo FM, et al. Optimization of mesenchymal stem cell expansion procedures by cell separation and culture conditions modification. Exp Hematol 2008; 36: 1014-21

[31] Dos Santos F, Andrade PZ, Boura JS, et al. Ex vivo expansion of human mesenchymal stem cells: a more effective cell proliferation kinetics and metabolism under hypoxia. J Cell Physiol 2010; 223: 27-35.

[32] Fehrer C, Brunauer R, Laschober G, et al. Reduced oxygen tension attenuates differentiation capacity of human mesenchymal stem cells and prolongs their lifespan. Aging Cell 2007; 6: 745-57.

[33] Muuller J, Benz K, Ahlers M, Gaissmaier C, Mollenhauer J. Hypoxic conditions during expansion culture prime human mesenchymal stromal precursor cells for chondrogenic differentiation in three-dimensional cultures. Cell Transplant 2011; [Epub ahead of print].

[34] Rosova I, Dao M, Capoccia B, Link D, Nolta JA. Hypoxic preconditioning results in increased motility and improved therapeutic potential of human mesenchymal stem cells. Stem Cells 2008; $26: 2173-82$

[35] Tamama K, Kawasaki H, Kerpedjieva SS, et al. Differential roles of hypoxia inducible factor subunits in multipotential stromal cells under hypoxic condition. J Cell Biochem 2011; 112: 804-17. 
[36] Lavrentieva A, Majore I, Kasper C, Hass R. Effects of hypoxic culture conditions on umbilical cord-derived human mesenchymal stem cells. Cell Commun Signal 2010; 8: 18.

[37] Nekanti U, Dastidar S, Venugopal P, Totey S, Ta M. Increased proliferation and analysis of differential gene expression in human Wharton's jelly-derived mesenchymal stromal cells under hypoxia. Int J Biol Sci 2010; 6: 499-512.

[38] Sekiya I, Larson BL, Smith JR, et al. Expansion of human adult stem cells from bone marrow stroma: conditions that maximize the yields of early progenitors and evaluate their quality. Stem Cells 2002; 20: 530-41.

[39] Farias VA, Linares-Fernandez JL, Penalver JL, et al. Human umbilical cord stromal stem cell express CD10 and exert contractile properties. Placenta 2011; 32: 86-95.

[40] Page RL, Ambady S, Holmes WF, et al. Induction of stem cell gene expression in adult human fibroblasts without transgenes. Cloning Stem Cells 2009; 11: 417-26.

[41] Toussaint O, Weemaels G, Debacq-Chainiaux F, ScharffetterKochanek K, Wlaschek M. Artefactual effects of oxygen on cell culture models of cellular senescence and stem cell biology. J Cell Physiol 2011; 226: 315-21.

[42] Forristal CE, Wright KL, Hanley NA, Oreffo RO, Houghton FD. Hypoxia inducible factors regulate pluripotency and proliferation in human embryonic stem cells cultured at reduced oxygen tensions. Reproduction 2010; 139: 85-97.

[43] Kaluz S, Kaluzova M, Stanbridge EJ. Regulation of gene expression by hypoxia: integration of the HIF-transduced hypoxic signal at the hypoxia-responsive element. Clin Chim Acta 2008; 395: 6-13.

[44] Moreno-Manzano V, Rodriguez-Jimenez FJ, Acena-Bonilla JL, et al. FM19G11, a new hypoxia-inducible factor (HIF) modulator, affects stem cell differentiation status. J Biol Chem 2010; 285: 1333-42.

[45] Bodnar AG, Ouellette M, Frolkis M, et al. Extension of life-span by introduction of telomerase into normal human cells. Science 1998; 279: 349-52.

[46] Morales CP, Gandia KG, Ramirez RD, et al. Characterisation of telomerase immortalised normal human oesophageal squamous cells. Gut 2003; 52: 327-33.

[47] Mitchell KE, Weiss ML, Mitchell BM, et al. Matrix cells from Wharton's jelly form neurons and glia. Stem Cells 2003; 21: 50-60.

[48] D'Ippolito G, Diabira S, Howard GA, Roos BA, Schiller PC. Low oxygen tension inhibits osteogenic differentiation and enhances stemness of human MIAMI cells. Bone 2006; 39: 513-22.

[49] Simonsen JL, Rosada C, Serakinci N, et al. Telomerase expression extends the proliferative life-span and maintains the osteogenic potential of human bone marrow stromal cells. Nat Biotechnol 2002; 20: 592-6.

[50] Wagner W, Bork S, Horn P, et al. Aging and replicative senescence have related effects on human stem and progenitor cells. PLoS One 2009; 4: e5846.

[51] Csete M. Oxygen in the cultivation of stem cells. Ann N Y Acad Sci 2005; 1049: 1-8.

[52] Ren H, Cao Y, Zhao Q, et al. Proliferation and differentiation of bone marrow stromal cells under hypoxic conditions. Biochem Biophys Res Commun 2006; 347: 12-21.

[53] Sotiropoulou PA, Perez SA, Salagianni M, Baxevanis CN, Papamichail M. Characterization of the optimal culture conditions for clinical scale production of human mesenchymal stem cells. Stem Cells 2006; 24: 462-71.

[54] Nekanti U, Mohanty L, Venugopal P, et al. Optimization and scaleup of Wharton's jelly-derived mesenchymal stem cells for clinical applications. Stem Cell Res 2010; 5: 244-54.

[55] Sarugaser R, Lickorish D, Baksh D, Hosseini MM, Davies JE. Human umbilical cord perivascular (HUCPV) cells: a source of mesenchymal progenitors. Stem Cells 2005; 23: 220-9.

[56] Cholewa D, Stiehl T, Schellenberg A, et al. Expansion of adipose mesenchymal stromal cells is affected by human platelet lysate and plating density. Cell Transplant 2011; [Epub ahead of print].
[57] Colter DC, Sekiya I, Prockop DJ. Identification of a subpopulation of rapidly self-renewing and multipotential adult stem cells in colonies of human marrow stromal cells. Proc Natl Acad Sci USA 2001; 98: 7841-5.

[58] Prockop DJ, Sekiya I, Colter DC. Isolation and characterization of rapidly self-renewing stem cells from cultures of human marrow stromal cells. Cytotherapy 2001; 3: 393-6.

[59] Liu H, Xue W, Ge G, et al. Hypoxic preconditioning advances CXCR4 and CXCR7 expression by activating HIF-1alpha in MSCs. Biochem Biophys Res Commun 2010; 401: 509-15.

[60] Bieback K, Hecker A, Kocaomer A, et al. Human alternatives to fetal bovine serum for the expansion of mesenchymal stromal cells from bone marrow. Stem Cells 2009; 27: 2331-41.

[61] Felka T, Schafer R, de ZP, Aicher WK. Animal serum-free expansion and differentiation of human mesenchymal stromal cells Cytotherapy 2010; 12: 143-53.

[62] Montzka K, Fuhrmann T, Woltje M, Brook GA. Expansion of human bone marrow-derived mesenchymal stromal cells: serumreduced medium is better than conventional medium. Cytotherapy 2010; $12: 587-92$.

[63] Shahdadfar A, Fronsdal K, Haug T, Reinholt FP, Brinchmann JE. In vitro expansion of human mesenchymal stem cells: choice of serum is a determinant of cell proliferation, differentiation, gene expression, and transcriptome stability. Stem Cells 2005; 23: 1357 66.

[64] Jung S, Sen A, Rosenberg L, Behie LA. Identification of growth and attachment factors for the serum-free isolation and expansion of human mesenchymal stromal cells. Cytotherapy 2010; 12: 63757.

[65] Bianco P, Robey PG, Simmons PJ. Mesenchymal stem cells: revisiting history, concepts, and assays. Cell Stem Cell 2008; 2 313-9.

[66] Simmons PJ, Torok-Storb B. Identification of stromal cell precursors in human bone marrow by a novel monoclonal antibody, STRO-1. Blood 1991; 78: 55-62.

[67] Sacchetti B, Funari A, Michienzi S, et al. Self-renewing osteoprogenitors in bone marrow sinusoids can organize a hematopoietic microenvironment. Cell 2007; 131: 324-36.

[68] Battula VL, Treml S, Bareiss PM, et al. Isolation of functionally distinct mesenchymal stem cell subsets using antibodies against CD56, CD271, and mesenchymal stem cell antigen-1. Haematologica 2009; 94: 173-84.

[69] Jarocha D, Lukasiewicz E, Majka M. Adventage of mesenchymal stem cells (MSC) expansion directly from purified bone marrow CD105+ and CD271+ cells. Folia Histochem Cytobiol 2008; 46 : 307-14.

[70] Mendez-Ferrer S, Michurina TV, Ferraro F, et al. Mesenchymal and haematopoietic stem cells form a unique bone marrow niche. Nature 2010; 466: 829-34.

[71] Nagoshi N, Shibata S, Kubota Y, et al. Ontogeny and multipotency of neural crest-derived stem cells in mouse bone marrow, dorsal root ganglia, and whisker pad. Cell Stem Cell 2008; 2: 392-403.

[72] Wislet-Gendebien S, Bruyere F, Hans G, et al. Nestin-positive mesenchymal stem cells favour the astroglial lineage in neural progenitors and stem cells by releasing active BMP4. BMC Neurosci 2004; 5: 33.

[73] Weiss ML, Medicetty S, Bledsoe AR, et al. Human umbilical cord matrix stem cells: preliminary characterization and effect of transplantation in a rodent model of Parkinson's disease. Stem Cells 2006; 24: 781-92.

[74] La Rocca G., Anzalone R, Corrao S, et al. Isolation and characterization of Oct-4+/HLA-G+ mesenchymal stem cells from human umbilical cord matrix: differentiation potential and detection of new markers. Histochem Cell Biol 2009; 131: 267-82.

[75] Davy P, Allsopp R. Hypoxia: are stem cells in it for the long run? Cell Cycle 2011; 10: 206-11.

[76] Smith LL, Coller HA, Roberts JM. Telomerase modulates expression of growth-controlling genes and enhances cell proliferation. Nat Cell Biol 2003; 5: 474-9.

This is an open access article licensed under the terms of the Creative Commons Attribution Non-Commercial License (http://creativecommons.org/ licenses/by-nc/3.0/), which permits unrestricted, non-commercial use, distribution and reproduction in any medium, provided the work is properly cited 